\title{
AVALIAÇÃO DE CULTIVARES DE PEPINO TIPO CAIPIRA SOB AMBIENTE PROTEGIDO EM DUAS ÉPOCAS DE SEMEADURA ${ }^{(1)}$
}

\author{
ANTONIO ISMAEL INÁCIO CARDOSO(2)
}

\begin{abstract}
RESUMO
Avaliaram-se sob cultivo protegido na Fazenda Experimental São Manuel (FCA/UNESP, Câmpus de Botucatu) quatro variedades (Branco Colonião, Caipira Hortec, Prêmio e Rubi) e três híbridos (Caipira AG-221, Guarani AG-370 e Safira) de pepino tipo caipira em duas épocas: verão e inverno. O delineamento experimental foi o de blocos ao acaso, com quatro repetiçōes e cinco plantas por parcela. O híbrido Safira foi o mais produtivo na semeadura de verão (41,3 frutos por planta), enquanto no inverno 'Prêmio' produziu menor número de frutos comercias (6,7 frutos por planta) que todos os demais. Iniciaram-se as colheitas, em média, 51 e 87 dias após a semeadura no verão e no inverno respectivamente. Os híbridos foram mais precoces que as variedades na semeadura de verão. Os frutos passavam do ponto mais rapidamente no cultivo de verão, apresentando maior massa média. Concluiuse que o híbrido Safira foi o melhor para o cultivo no verão, enquanto no inverno a produtividade de todas as cultivares foi muito prejudicada.
\end{abstract}

Palavras-chave: Cucumis sativus, produção, verão, inverno.

\section{ABSTRACT \\ EVALUATION OF “CAIPIRA” CUCUMBER CULTIVARS UNDER PROTECTED CULTIVATION IN TWO SOWING DATES}

Four varieties (Branco Colonião, Caipira Hortec, Prêmio and Rubi) and three hybrids (Caipira AG-221, Guarani AG-370 and Safira) of cucumber were evaluated under protected cultivation at São Manuel Experimental Farm (FCA/UNESP) during summer and winter seasons. The experimental model was randomized block, with four replicates of five plants per plot. 'Safira' $F_{1}$ hybrid presented the highest yield during the summer ( 41.3 fruits/plant), while 'Premio' $F_{1}$ hybrid had the smallest commercial yield (6.7 fruits/plant) during winter. In average, harvesting was initiated 51 days after sowing in the summer, and after 87 days in the winter. Also hybrids were more precocious than open pollinated cultivars, in the summer. Fruits surpassed commercial weight earlier in the summer than in the winter. It was concluded that 'Safira' $F_{1}$ hybrid was the best cultivar for the summer, while in the winter all cultivars presented lower yield.

Key words: Cucumis sativus, yield, summer, winter.

\section{INTRODUÇÃO}

O pepino (Cucumis sativus) tem crescido de importância na comercialização de hortaliças, sendo muito apreciado e consumido em todo Brasil, na forma crua de seu fruto imaturo em saladas, curtido em salmoura ou vinagre e raramente maduro e cozido. Em 1998, foram comercializadas 34.508 toneladas na CEAGESP (Fnp Consultoria e Comércio, 2000). Segundo Lopes (1991), além do valor econômico e alimentar, o cultivo de Cucurbitáceas também tem grande importância social, na geração de empregos diretos e indiretos, pois demanda grande quantidade de mão-de-obra, desde o cultivo até a comercialização.
O pepino é uma espécie não adaptada ao cultivo sob baixas temperaturas, sendo o desenvolvimento da planta favorecido por temperaturas superiores a $20{ }^{\circ} \mathrm{C}$ (LOWER e EDWARDS, 1986). Temperaturas inferiores a 20 ${ }^{\circ} \mathrm{C}$ afetam a absorção de água e nutrientes pelo sistema radicular (Robinson e DECKER-WALTERS, 1999). Esse foi um dos motivos pelos quais os produtores passaram a cultivar pepino em ambiente protegido a partir da década de 80 , ocupando o segundo lugar entre as principais hortaliças, seguido do tomate (SILVA et al., 1995). Dentre as Cucurbitáceas, é a espécie mais cultivada em ambiente protegido em todo o mundo. Existem relatos do "cultivo forçado" de pepino desde a época do Império Romano (Robinson e DeCKer-Walters, 1999).

$\left({ }^{1}\right)$ Recebido para publicação em 27 de junho de 2001 e aceito em 28 de fevereiro de 2002.

$\left(^{2}\right)$ Departamento de Produção Vegetal, Faculdade de Ciências Agronômicas, Universidade Estadual Paulista, Caixa Postal 237, 18603-970 Botucatu (SP). E-mail: ismaeldh@fca.unesp.br 
Aumentos de produtividade no sistema protegido, em relação ao cultivo em campo aberto, têm sido relatados no Brasil, variando de $0,3 \%$ a $46,3 \%$, dependendo da cultivar (ReIs et al., 1991), 48,5\% (ReIs et al., 1992) e de 55,0\% a 79,6\% (Oliveira et al., 1995).

A maioria dos híbridos de pepino tipo japonês são partenocárpicos, por isso podem ser cultivados em ambiente protegido o ano todo (FIlgueIra, 2000). Partenocarpia natural já foi descrita em pepino ainda no século 19, entretanto somente na década de 50 é que foi comercialmente utilizada nos plantios em estufa na Holanda (Ponti, 1976). No fim da década de 60, a maioria das variedades de pepino cultivadas na Europa já eram partenocárpicas, possibilitando seu plantio em ambiente protegido, com ausência de insetos polinizadores (PIKE e Peterson, 1969). As variedades e os híbridos de pepino caipira, atualmente cultivados no Brasil, não apresentam partenocarpia, dificultando seu plantio no inverno em estufas fechadas, em virtude de redução na entrada de insetos polinizadores. Mesmo assim, muitos produtores têm plantado cultivares de pepino caipira em estufas no inverno por causa da procura desse produto, sobretudo nos mercados do interior do Estado de São Paulo.

A utilização de híbridos de pepino se tornou comum em razão da maior produtividade, da uniformidade, da qualidade dos frutos e do baixo custo da semente em relação ao custo total da cultura: 0,8\% (VIGGIANO, 1994).

A superioridade de híbridos $F_{1}$ de pepino foi constatada há mais de oito décadas, em 1916, por Hayes e Jones citados por FilgueIra et al. (1986). Nessa ocasiāo, verificou-se a presença de heterose para produção de frutos e número de frutos por planta. Entretanto, o primeiro híbrido comercial de pepino, "Burpee Hybrid", foi obtido por O. Shifriss em 1945, e introduzido pela "Burpee Seed Company" (Robinson e Decker-Walters, 1999).

Trabalhando com linhagens e híbridos $F_{1}$ experimentais de pepino caipira, em cultivo rasteiro, FiLgUeIRA et al. (1986) relataram heterose positiva tanto para produção total como para produção precoce.

CAmargo et al. (1993) destacaram que, no Brasil, durante a década de 80 , foram lançadas diversas cultivares de hortaliças. Entretanto, segundo pesquisa realizada por TRANI et al. (1997), existe praticamente consenso dos extensionistas quanto à necessidade de novas cultivares, bem como a instalação de experimentos regionais de avaliação das cultivares disponíveis visando à recomendação aos olericultores. No período de 198993 reduziram-se as atividades de avaliação de cultivares, tanto nas universidades como nas instituições de pesquisa, passando de $17,7 \%$ dos trabalhos apresentados no Congresso Brasileiro de Olericultura de 1989 para
8,5\% em 1993, não atendendo a demanda por pesquisa nessa área (Buso e Nascimento, 1994).

Além da escassez de pesquisas com cultivares de pepino caipira sob ambiente protegido, vários híbridos têm sido lançados no mercado nos últimos anos. Existem, porém, poucas informações sobre seu comportamento que, para qualquer genótipo, pode ser afetado pelo local, época e condiçóes de cultivo. DEMATTÊ (1978), trabalhando em Campinas (SP) com cultivares do grupo Aodai, relatou as cultivares Palomar e Rio Verde como as favorecidas pela semeadura em maio, enquanto a Aodai, pela semeadura em dezembro. Já a cultivar Marketer foi pouco influenciada pelas variações ambientais, comparativamente às demais cultivares estudadas.

Este trabalho teve por objetivo avaliar diferentes cultivares de pepino tipo caipira sob cultivo protegido nas condições de verão e de inverno em São Manuel (SP).

\section{MATERIAL E MÉTODOS}

Os experimentos foram realizados na Fazenda Experimental São Manuel, localizada no município de São Manuel (SP), pertencente à Faculdade de Ciências Agronômicas (FCA) da Universidade Estadual Paulista (UNESP), Câmpus de Botucatu. A localidade apresenta as seguintes coordenadas geográficas: longitude $48^{\circ} 34^{\prime} \mathrm{W}$, latitude 22\%44'S e altitude média de 750 metros.

Utilizaram-se casas de vegetação não climatizadas com pé-direito aproximado de $2 \mathrm{~m}$, largura de $5 \mathrm{~m}$, comprimento de $20 \mathrm{~m}$, modelo em arco, e cobertura com plástico de $100 \mathrm{~mm}$.

Avaliaram-se quatro variedades (Branco Colonião - Hortec, Caipira - Hortec, Prêmio - Sakata/Agroflora e Rubi - Sakata/Agroflora) e três híbridos (Caipira AG221 - SVS/Horticeres, Guarani AG-370 - SVS/ Horticeres e Safira - Sakata/Agroflora) de pepino tipo caipira em duas épocas: verão e inverno.

O delineamento experimental adotado foi o de blocos ao acaso, com quatro repetições e cinco plantas por parcela. O espaçamento utilizado foi de $1,0 \times 0,5$ metro.

Para a garantia do estande ideal, evitando-se falhas e desuniformidade no desenvolvimento inicial das plantas, foram feitas mudas em bandejas de poliestireno expandido de 128 células (modelo CM 128-62), com substrato comercial.

A adubação constou de aplicação de composto por ocasião do preparo do solo $\left(5 \mathrm{~L} . \mathrm{m}^{-2}\right)$, adubo formulado 4-14-8 (150 g.m $\mathrm{m}^{-1}$ de sulco) e nitrocálcio (20 g. $\mathrm{m}^{-1}$ de sulco). As adubações em cobertura foram realizadas, a cada 14 dias, com $5 \mathrm{~g}$ de nitrocálcio colocados ao lado de cada planta; utilizou-se irrigação localizada por meio de gotejadores. 
No inverno, a semeadura e o transplante foram realizados, respectivamente, em 27/5/98 e 15/6/98. As colheitas, em número de três por semana, iniciaram-se em 19/8/98 e concluíram-se em 9/10/98, aos 86 e 137 dias após a semeadura respectivamente.

No verão, a semeadura e o transplante foram realizados, respectivamente, em 3/12/98 e 22/12/98. As colheitas, em número de três por semana, iniciaram-se em 19/1/99 e concluíram-se em 9/3/99, aos 49 e 96 dias após a semeadura respectivamente.

Em ambas as épocas as plantas foram tutoradas com a utilização de taquaras de bambu, eliminando-se todas as brotaçôes laterais e flores femininas até o sexto nó da haste principal. Deixaram-se as demais brotaçóes com crescimento livre. Ao atingir a altura do arame, aproximadamente 1,8 m, realizou-se a eliminação da gema apical.

Foram avaliadas as seguintes características: dias para início de colheita, produção de frutos (número e massa) e massa média de fruto. Na semeadura de inverno, por causa de elevada incidência de frutos deformados, classificaram-se os frutos em comerciais e não comerciais. No experimento de verão, avaliou-se apenas a produção de frutos comerciais, pois quase não se observaram frutos defeituosos. Os frutos eram colhidos quando atingiam aproximadamente $15 \mathrm{~cm}$ de comprimento.

Após as análises da variância, as médias foram comparadas pelo teste de Duncan ao nível de 5\%. As características, cujos valores foram expressos em números de frutos, foram inicialmente transformadas em raiz quadrada do valor antes de serem analisadas estatisticamente. Os resultados estão apresentados, entretanto, com as médias originais.

\section{RESULTADOS E DISCUSSÃO}

O quadro 1 apresenta as médias obtidas na semeadura de verão para as características número de dias para início de colheita, número e produção $(\mathrm{g})$ de frutos por planta e massa média de fruto, com as respectivas comparaçóes pelo teste de Duncan (5\%).

As cultivares de polinização aberta, Branco Coloniāo e Caipira Hortec, foram as mais tardias, com início de colheita dez dias após os híbridos mais precoces: Caipira AG-221 e Guarani. Embora as diferenças nem sempre tenham sido significativas, as três cultivares mais tardias (Branco Colonião, Caipira Hortec e Rubi) são variedades de polinização aberta, enquanto as quatro mais precoces são híbridos $F_{1}$. A tendência observada quanto à precocidade de produção foi semelhante à relatada na literatura, ou seja, os híbridos são mais precoces que as variedades (WeHNER e Miller, 1985; Filgueira et al., 1986; CuI et al., 1992; Viggiano, 1994; Li et al., 1995).

Quanto à produção, o híbrido Safira foi superior, tanto em número de frutos como em massa, a todos os demais, que não diferiram entre si. Não foi observada diferença na massa média de frutos, visto que o ponto de colheita era aproximadamente o mesmo para todas as variedades, ou seja, frutos com cerca de 12 a $15 \mathrm{~cm}$ de comprimento.

O quadro 2 apresenta as médias obtidas na semeadura de inverno para as características número de dias para início de colheita, número e produção $(\mathrm{g})$ de frutos total e comercial por planta e massa média de fruto, com as respectivas comparaçóes pelo teste de Duncan (5\%).

Quadro 1. Médias de dias para início de colheita, produção de frutos por planta e massa média de frutos na semeadura de verão. São Manuel (SP), 1998-99

\begin{tabular}{lcccc}
\hline Cultivares & $\begin{array}{c}\text { Início } \\
\text { da colheita }\end{array}$ & $\begin{array}{c}\text { Número } \\
\text { de frutos }\end{array}$ & Produção & Massa \\
\hline Branco Coloniāo & dias & & & \\
Caipira AG-221 & $58,25 \mathrm{a}$ & $27,4 \mathrm{~b}$ & $7.439 \mathrm{~b}$ & $279,2 \mathrm{a}$ \\
Caipira Hortec & $47,00 \mathrm{c}$ & $22,6 \mathrm{~b}$ & $6.437 \mathrm{~b}$ & $284,6 \mathrm{a}$ \\
Guarani AG-370 & $57,25 \mathrm{a}$ & $19,1 \mathrm{~b}$ & $5.601 \mathrm{~b}$ & $297,6 \mathrm{a}$ \\
Prêmio & $48,00 \mathrm{c}$ & $27,7 \mathrm{~b}$ & $8.181 \mathrm{~b}$ & $294,1 \mathrm{a}$ \\
Rubi & $48,50 \mathrm{bc}$ & $24,5 \mathrm{~b}$ & $6.915 \mathrm{~b}$ & $283,6 \mathrm{a}$ \\
Safira & $52,75 \mathrm{~b}$ & $23,2 \mathrm{~b}$ & $7.005 \mathrm{~b}$ & $300,8 \mathrm{a}$ \\
\hline CV $(\%)$ & $49,00 \mathrm{bc}$ & $41,3 \mathrm{a}$ & $11.558 \mathrm{a}$ & $281,3 \mathrm{a}$ \\
\hline
\end{tabular}

Médias seguidas pela mesma letra, nas colunas, não diferem pelo teste de Duncan ao nível de 5\%. 
Quadro 2. Médias de dias para início de colheita, número e produção de frutos por planta e massa média de frutos na semeadura de inverno. São Manuel (SP), 1998

\begin{tabular}{|c|c|c|c|c|c|c|}
\hline \multirow{2}{*}{ Cultivares } & \multirow{2}{*}{$\begin{array}{c}\text { Início } \\
\text { da colheita }\end{array}$} & \multicolumn{2}{|c|}{ Número de frutos } & \multirow{2}{*}{$\begin{array}{c}\text { Produção } \\
\text { total }\end{array}$} & \multirow{2}{*}{$\begin{array}{l}\text { Produção } \\
\text { comercial }\end{array}$} & \multirow{2}{*}{$\begin{array}{l}\text { Massa } \\
\text { média }\end{array}$} \\
\hline & & Total & Comercial & & & \\
\hline & & dia & & 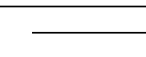 & $\mathrm{g}$ & 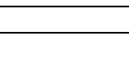 \\
\hline Branco Colonião & $89,50 \mathrm{a}$ & $17,3 \mathrm{a}$ & $14,6 \mathrm{a}$ & $3.683 \mathrm{a}$ & $3.297 \mathrm{a}$ & $224,5 \mathrm{ab}$ \\
\hline Caipira AG-221 & $86,00 \mathrm{a}$ & $19,7 \mathrm{a}$ & $13,0 \mathrm{a}$ & $3.807 \mathrm{a}$ & $2.941 \mathrm{a}$ & $225,5 \mathrm{ab}$ \\
\hline Caipira Hortec & 87,75 a & $18,3 \mathrm{a}$ & $11,9 \mathrm{a}$ & $3.666 \mathrm{a}$ & $2.777 \mathrm{ab}$ & $234,2 \mathrm{a}$ \\
\hline Guarani AG-370 & $86,00 \mathrm{a}$ & $20,7 \mathrm{a}$ & 13,6 a & $3.787 \mathrm{a}$ & $2.878 \mathrm{ab}$ & $212,1 \mathrm{ab}$ \\
\hline Prêmio & $86,00 \mathrm{a}$ & $16,2 \mathrm{a}$ & $6,7 \mathrm{~b}$ & $2.710 \mathrm{a}$ & $1.392 \mathrm{~b}$ & $206,0 \mathrm{~b}$ \\
\hline Rubi & $87,33 \mathrm{a}$ & $16,2 \mathrm{a}$ & $13,7 \mathrm{a}$ & $3.380 \mathrm{a}$ & $3.006 \mathrm{a}$ & $219,1 \mathrm{a}$ \\
\hline Safira & $86,00 \mathrm{a}$ & $19,4 \mathrm{a}$ & $12,3 \mathrm{a}$ & $3.536 \mathrm{a}$ & $2.633 \mathrm{ab}$ & $211,7 \mathrm{ab}$ \\
\hline CV (\%) & 2,2 & 11,3 & 13,7 & 25,4 & 30,0 & 5,7 \\
\hline
\end{tabular}

Médias seguidas pela mesma letra, nas colunas, não diferem pelo teste de Duncan ao nível de 5\%.

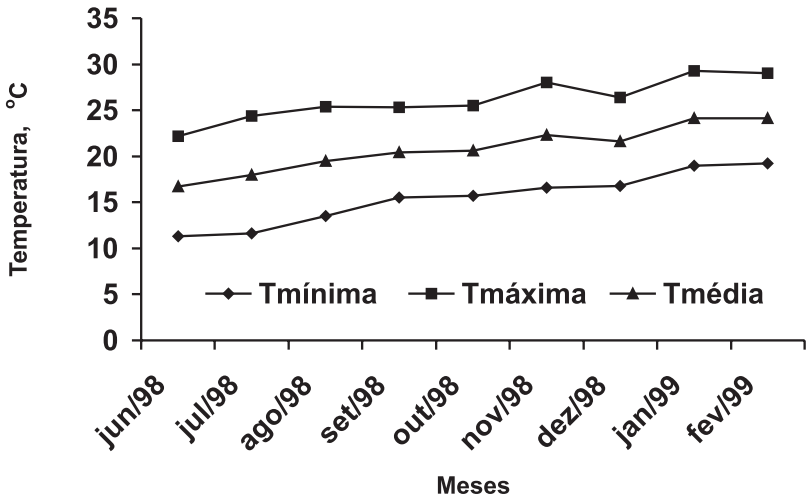

Figura 1. Temperaturas médias, máximas e mínimas mensais coletadas na estação meteorológica, localizada em campo aberto, da Fazenda Experimental São Manuel, no período em que foram realizados os experimentos, 1998-99.

Não foram observadas diferenças no ciclo entre os materiais, com início de colheitas com quase três meses após a semeadura. Comparando-se com a semeadura de verão, a colheita de inverno foi retardada, devido ao desenvolvimento mais lento das plantas (Figura 1). Baixas temperaturas prolongam o ciclo vegetativo da planta (CANIZARES, 1998). Em média, iniciaram-se as colheitas 35 dias mais tarde na semeadura de inverno que na de verão. Esses resultados estão coerentes com os de Miller e QuisenberRY (1976); esses autores notaram que temperaturas baixas retardam o florescimento e a época de colheita de pepino. O pepino é uma espécie não adaptada ao cultivo sob baixas temperaturas, sendo o desenvolvimento da planta favorecido por temperaturas superiores a $20^{\circ} \mathrm{C}$ (LOWER e EDWARDS, 1986). Entretanto, o período de colheita não foi alterado, mantendo-se em cerca de 50 dias nas duas épocas.
Não foi detectada diferença na produção total de frutos por planta, tanto em número como em massa. Entretanto, devido ao grande número de frutos deformados, o híbrido Prêmio foi inferior em número de frutos comerciais a todos os demais, que não diferiram entre si. Talvez o motivo seja o fato de este híbrido ser recomendado para cultivo em campo aberto no verão, com a finalidade de colheita de frutos para a indústria de processamento (picles), sendo o consumo in natura a segunda alternativa de utilização; não houve melhora genética visando a este mercado.

Comparando-se as duas épocas, observou-se que a produtividade foi bem menor no inverno, mostrando, novamente, a pequena adaptação da cultura a baixas temperaturas. Sob tais condições, além de haver prolongamento do período vegetativo, há diminuição na eficiência do sistema radicular, reduzindo a absorção de água e nutrientes, além de causar distúrbios fisiológicos (Canizares, 1998). Slack E Hand (1983) observaram uma perda quase linear na produtividade em pepino com a redução da temperatura, principalmente a noturna.

Deve-se ressaltar, também, que devido às baixas temperaturas as cortinas laterais ficavam abaixadas a maior parte do dia, visando aumentar a temperatura interna da estufa. Essa prática, associada a baixas temperaturas externas, reduz a eficiência dos insetos polinizadores, fundamentais na produção de pepino (Amaral et al., 1963; Robinson e Decker-Walters, 1999; Filgueira, 2000), principalmente porque nenhuma das cultivares utilizadas é partenocárpica, necessitando de polinização entomófila para promover o pegamento e desenvolvimento dos frutos.

A maioria dos híbridos de pepino tipo japonês é partenocárpica, por isso pode ser cultivada em ambiente protegido o ano todo (FILGUeIRA, 2000). Já as variedades 
e os híbridos de pepino caipira não apresentam partenocarpia, o que dificulta o seu plantio no inverno em estufas fechadas, devido à redução na entrada de insetos polinizadores. Além disso, nos híbridos ginóicos, há necessidade de um polinizador, plantas monóicas, com flores masculinas ( $10 \%$ a $15 \%$ ), que se tornam insuficientes se a população de insetos polinizadores for pequena.

Quanto à massa média de fruto, o híbrido Prêmio apresentou frutos menores que os das variedades Caipira Hortec e Rubi, confirmando sua menor adaptação ao sistema de cultivo para consumo in natura. Em média, os frutos colhidos nessa época foram menores (média de todas as cultivares de 219 gramas por fruto) que os do verão (289 gramas por fruto). Como foram realizadas três colheitas por semana, sempre havia frutos passados do ponto de consumo em algumas parcelas; no verão, por causa das temperaturas mais elevadas, os frutos cresceram mais rapidamente, favorecendo a produção de frutos maiores.

\section{CONCLUSÕES}

1. O híbrido Safira foi o mais produtivo na semeadura de verão.

2. Em média, os híbridos foram mais precoces que as cultivares de polinização aberta na semeadura de verão.

3. O início de colheita foi mais precoce e a produtividade superior na semeadura de verão que na de inverno.

4. Não é recomendado o cultivo de pepinos não partenocárpicos em ambiente protegido, em que não há circulação de insetos polinizadores.

\section{REFERÊNCIAS BIBLIOGRÁFICAS}

AMARAL, E.; MITIDIERI, J.; VENCOVSKY, R. Estudos sobre o comportamento da Apis mellifera na visita às flores do Cucumis sativus. Olericultura, Campinas, v.3, p.181-193, 1963.

BUSO, J.A.; NASCIMENTO, W.M. O papel das instituiçôes oficiais de pesquisa e desenvolvimento na indústria de sementes de hortaliças. Horticultura Brasileira, Brasília, v.12, n.2, p.244-250, 1994.

CAMARGO, A.M.M.P.; CASPER, D.V.; TAKAES, M.; CAMARGO-FILHO, W.P. Estratégia de ação para produção orientada de hortaliças no Estado de São Paulo. Informaçôes Econômicas, São Paulo, v.23, n.11, 45-60, 1993.

CAÑIZARES, K.A.L. A cultura de pepino. In: GOTO, R.; TIVELLI, S.W. Produção de hortaliças em ambiente protegido: condiçōes subtropicais. São Paulo: Fundação Editora da Unesp, 1998. p.195-223.
CUI, H.W.; QI, Y.T.; LIU, J.H.; REN, Z.B. Correlation between parents and $\mathrm{F} 1$ progeny in earliness heterosis and the estimation of traits limits of parents. Report Cucurbit Genetics Cooperative, n.15, p.13-16, 1992.

DEMATTÊ, M.E.S.P. Comportamento de cultivares de pepino (Cucumis sativus L.) em duas épocas de semeadura. 1978. 109f. Dissertação (Mestrado) Escola Superior de Agricultura "Luiz de Queiroz", Universidade de São Paulo, Piracicaba.

FILGUEIRA, F.A.R. Novo manual de olericultura: agrotecnologia moderna na produção e comercialização de hortaliças. Viçosa: Editora UFV, 2000. 402p.

FILGUEIRA, F.A.R.; GIORDANO, L.B.; FERREIRA, P.E.; VECCHIA, P.T.D. Avaliação de híbridos F1 de pepino do tipo caipira. Horticultura Brasileira, Brasília, v.4, n.1, p.17-20, 1986.

FNP Consutoria \& Comércio. Agrianual 2000. São Paulo, 2000. 546p.

LI, J.W.; LI, J.W.; WEI, Z.D. Genetic analysis for major agronomic characters in cucumber (Cucumis sativus L.). Acta Horticulturae, Wageningen, v.402, p.388-391, 1995.

LOPES, J.F. I Simpósio Brasileiro sobre cucurbitáceas: Palestra de Abertura. Horticultura Brasileira, Brasília, v.9, n.2, p.98-99, 1991.

LOWER, R.L.; EDWARDS, M.D. Cucumber breeding. In: BASSET, M.J. (Ed.). Breeding vegetable crops. Westport: Avi Publishing, 1986. p.173-207.

MILLER, J.C.; QUISENBERRY, J.E. Inheritance of time of flowering and its relationship to crop maturity in cucumber. Journal of the American Society for Horticultural Science, Alexandria, v.101, p.497-500, 1976.

OLIVEIRA, A.C.B.; ARAUJO, M.L.; LEAL, N.R. Avaliação do comportamento de três cultivares de pepino submetidas ao cultivo sob estrutura de proteção e a céu aberto na região Norte Fluminense-RJ. Horticultura Brasileira, Brasília, v.13, n.1, p.99, 1995.

PIKE, L.M.; PETERSON, C.E. Inheritance of parthenocarpy in the cucumber (Cucumis sativus L.). Euphytica, Dordrecht, v.18, p.101-105, 1969.

PONTI, O.M.B. Breeding parthenocarpic pickling cucumbers (Cucumis sativus L.): necessity, genetical possibilities, environmental influences and selection criteria. Euphytica, Dordrecht, v.25, p.29-40, 1976. 
REIS, N.V.B.; HORINO, Y.; OLIVEIRA, C.A.S.; BOITEUX, L.S. Influência da radiação fotossinteticamente ativa (RFA) sobre os componentes de produção de nove genótipos de pepino plantado a céu aberto e sob estufas plásticas. Horticultura Brasileira, Brasília, v.9, n.1, p.55, 1991.

REIS, N.V.B.; HORINO, Y.; OLIVEIRA, C.A.S.; BOITEUX, L.S.; LOPES, J.F. Influência de temperatura - graus-dia - sobre a produção de pepino sob cultivo protegido e a céu aberto. Horticultura Brasileira, Brasília, v.10, n.1., p.65, 1992.

ROBINSON, R.W.; DECKER-WALTERS, D.S. Cucurbits. Cambridge: CAB International, 1999. 226p.

SILVA, A.A.; SOPRANO, E.; VIZZOTTO, V.J.; GRANZOTTO, M.S. Caracterizaçāo de deficiências nutricionais em pepineiro. Santa Catarina: EPAGRI, 1995. 35p.
SLACK, G.; HAND, D.W. The effect of day and night temperatures on the growth, development and yield of glasshouse cucumbers. Journal of Horticultural Science, Ashford, v.58, p.567-573, 1983.

TRANI, P.E.; GROPPO, G.A.; SILVA, M.C.P.; BURKE, T.J. Diagnóstico sobre a produção de hortaliças no estado de São Paulo. Horticultura Brasileira, Brasília, v.15, n.1, p.19-24, 1997.

VIGGIANO, J. Hortaliças: cultivares e sementes. Horticultura Brasileira, Brasília, v.12, n.2, p.252254, 1994.

WEHNER, T.C.; MILLER, C.H. Effect of gynoecious expression on yield and earliness of a fresh-marked cucumber hybrid. Journal of the American Society for Horticultural Science, Alexandria, v.110, n.4, p.464-466, 1985. 